\title{
Animal Models of Diabetic Neuropathic Pain
}

Authors

Affiliation

\author{
F. Gao, Z. M. Zheng
}

Department of Endocrinology, First Hospital of Shijiazhuang City, Shijiazhuang, China

\section{Key words \\ - diabetes \\ neuropathic pain \\ - animal models}

\section{Abstract \\ $\nabla$}

Diabetic neuropathy is a common complication of diabetes. It occurs in approximately $10-20 \%$ of patients with diabetes, or roughly $40-50 \%$ patients with diabetic neuropathy. However, the pathogenesis of diabetic neuropathic pain is still largely unknown. Several animal models have been used to study the underlying mechanisms for this complication. Some commonly used animal models include streptozotocin-induced rat and mouse models, diet/nutrition-induced models, combination of chemically- and nutritioninduced model, Zucker diabetic fatty rat model, type 1 insulinopenic BB/Wor and type 2 hyper-

\section{Introduction}

$\nabla$

Diabetes mellitus (DM) is the fourth or fifth leading cause of death in most developed countries (Richard et al., 2013). In many developing countries, there is substantial evidence showing that its prevalence is growing (Richard et al., 2013). Despite advancement in diabetes diagnosis, prevention, and treatment, in 2011, 34 million patients had diabetes worldwide (WHO, 2013). Diabetes complications could lead to disability, reduced quality of life, and death. In 2011, 4.6 million patients died of this disease (Richard et al., 2013).

Clinical manifestations of diabetes complications vary for different people; it may affect various parts of the body. In addition, no internationally agreed standards exist for diagnosing and assessing diabetes complications. Diabetic neuropathy is a common serious complication of diabetes. Approximately $50 \%$ of diabetes patients suffer from this complication (Diabetes in America 1995, Boulton 2004). Approximately $10-20 \%$ of patients with DM experienced painful symptoms, or roughly $40-50 \%$ patients with diabetic neuropathy had neuropathic pain (Veves et al., 2008). insulinemic diabetic BBZDR/Wor rat models, and transgenic/knock-out models. Even though the manifestations of diabetic neuropathic pain vary from thermal or chemical hyperalgesia, thermal or chemical hypoalgeia, allodynia, to spontaneous pain, some pathogenesis factors are shared among these symptoms. Increased AR activity, oxidative-nitrosative stress, protein kinase C, PARP and ACE activations, C-peptide deficiency, impaired neurotrophism, and proinflammatory responses have been identified in the development of diabetic neuropathic pain. This review discusses selected animal models for diabetic neuropathic pain, as well as some commonly shared pathways in these models.

Symptoms of neuropathic pain range from abnormal sensations such as parethesia, allodynia, hyperalgesia, to spontaneous pain that could seriously affect quality of life (Calcutt 2002; Mondelli et al., 2012). Neuropathic pain was defined as pain that is initiated or caused by a primary lesion or dysfunction or transitory perturbation in the peripheral or central nervous system. It could be an increased responsiveness to different innocuous and painful mechanical, thermal, or chemical stimuli. (Merskey, Bogduk 1994; Devor, Seltzer 1999). Pathogenesis of diabetic neuropathic pain is mostly unknown. Some studies showed that impaired cutaneous endothelium-related vasodilation and C-fibermediated vasoconstriction as well as increased sural nerve epineurial blood flow may be associated with this complication. (Quattrini et al., 2007; Eaton et al., 2003; Bierhaus et al., 2012). Most knowledge of the disease pathogenesis has been gained from studies in diabetic rat and mouse models. The models that have been mostly studied include streptozotocin-induced rats and mice, high-fat diet-fed mice, combination of chemically- and nutrition-induced model, spontaneous or genetically derived model, including
Department of Endocrinology First Hospital of Shijiazhuang

City

Shijiazhuang 050011

China

gaofokok@163.com 
Zucker diabetic fatty rats, type 1 insulinopenic BB/Wor and type 2 hyperinsulinemic diabetic BBZDR/Wor rats, nonobese diabetic, Akita mice, and leptin- and leptin-receptor-deficient mice. Some techniques have been used to assess the behavioral responses to external stimuli in diabetic animals (i.e., thermal and mechanical hyper- and hypoalgesia, tactile allodynia, as well as formalininduced spontaneous nociceptive behavior). This review focuses on the discussion of selected animal models that have been proven to be useful in studying the underlying mechanisms of diabetic neuropathic pain.

\section{Streptozotocin-Induced Diabetic Rats and Mice}

$\nabla$

Streptozotocin (2-deoxy-2(3-methyl-3-nitrosoureido)-D-glucopyranose) is a nitrosourea analogue. It is toxic to the pancreatic insulin-secreting $\beta$-cells by damaging its DNA (Szkudelski 2001; Lenzen et al., 2008). It is similar to glucose and could be transported via glucose transporter GLUT2. The nitrosoamide moiety of streptozotocin is responsible for its toxicity. The establishment of streptozotocin-induced diabetes model is relatively simple, with one time injection either intraperitioneally or intravenously. Therefore, the streptozotocin-induced diabetic rat has been widely used to study mechanism of diabetic neuropathic pain and to evaluate potential therapies.

Various doses of streptozotocin (35-200 $\mathrm{mg} / \mathrm{kg}$ in rats or mice) have been studied in animal models (Srinivasan, Ramarao 2007; Jafarnejad et al., 2008). The susceptibility of animal to streptozotocin depends on age, species, and strain. Different dosages may lead to different levels of $\beta$-cell impairment in pancreas. Higher dose streptozotocin injection induced diabetes is similar to type I insulin-dependent diabetes in humans: within $72 \mathrm{~h}$ of injection, most rats become hyperglycemic, lowered glucose-stimulated insulin secretion, and decreased glucose intolerance. In about $41 / 2$ weeks after injection, streptozotocin-treated rats exhibit behavioral signs of diabetic neuropathic pain, including significant reduction in the withdrawal threshold to mechanical pressure and the latency to withdrawal from a noxious thermal stimulus (Morrow, 2004).

Animal model of type 2 diabetes has been induced by combination of streptozotocin and nicotinamide (NA) administration in adult rats. NA is administrated to partially protect insulinsecreting $\beta$ cells against streptozotocin. The protective mechanism is thought to partially due to the inhibition of PARP-1 activity, preventing depletion of $\mathrm{NAD}^{+}$and ATP in the cells exposed to streptozotocin. The severity of diabetes in this animal model depends on the doses of streptozotocin and NA. The hyperglycemia level could range from mild to severe (Szkudelski, 2012).

Interestingly, studies showed that a single injection of streptozotocin $(80-100 \mathrm{mg} / \mathrm{kg})$ into neonatal rats or immediately after birth, those rats will develop type II diabetes in the adult age (Bonner-Weir et al., 1981; Portha et al., 1994). Rats with shortterm diabetes develop neuropathic pain, whereas those with longer-term diabetes and diabetic mice typically display manifestations of both painful and insensate neuropathy, or insensate neuropathy only (Obrosova, 2009).

Thermal hyperalgesia is an increased sensitivity to pain, which may be caused by damage to nociceptors or peripheral nerves. It has been studied in streptozotocin induced animals with shortterm (2-8 weeks) diabetes (Calcutt et al., 2004; Cameron et al., 2001; Cameron et al., 2001; Li et al., 2005). The underlying mechanisms have been identified to be related to increased aldose reductase (AR), protein kinase $\mathrm{C}$ (PKC), poly (ADP-ribose) polymerase (PARP), angiotensin converting enzyme (ACE) activities, toll-like receptor 4, and oxidative stress (Meller et al., 1992; Cotter et al., 2002; Obrosova et al., 2008; Yan et al., 2012). It was shown that subsequent activation of soluble guanylate cyclase in the lumbar spinal cord could mediate thermal hyperalgesia. Increased excitability of dorsal root ganglion neurons and expression of Nav1.7 and p-EPK1/2 has been identified in thermal hyperalgesia (Zhang et al., 2013). In addition, methylglyoxal treatment for thermal hyperalgesis could induce post-translational modification of the nociceptor-specific sodium channel Nav 1.8, reduce nerve conduction velocity, neurosecretion of calcitonin gene-related peptide, and increase cyclooxygenase-2 (COX-2) expression (Bierhaus, Nawroth 2012). In a chemical hyperalgesia induced by formalin in streptozotocin animal model, it has also been shown that peripheral activation of CB1 and $\mathrm{CB} 2$ receptor mediate the antinociceptive effect of exogenous and endogenous anandamide (Schreiber et al., 2012).

Thermal hypoalgesia occurs when nociceptive stimuli are interrupted or decreased in the pathway. It is a clinical manifestation in patients with advanced diabetic neuropathy. This condition has been studied in long-term streptozotocin-induced diabetes models (Calcutt et al., 2004; Cameron et al., 2005). Interestingly, most above mentioned mechanisms for the increased thermal sensitivity in the short-term animal models were also involved in long-term thermal hypoalgesia development. For example, increased AR activity, activation of the AGE/RAGE axis, oxidative-nitrosative stress, as well as activation of ACE, and PARP were identified in thermal hypoalgesia (Calcutt et al., 2004; Li et al., 2005; Cameron et al., 2005; Ilnytska et al., 2006; Drel et al., 2007; Vareniuk et al., 2008; Francis et al., 2008; Sumner et al., 2003). In addition, studies showed that neurotrophic factor deficiency may as well contribute to diabetes-induced thermal sensory loss (Sumner et al., 2003). Epidermal nerve fiber loss is evident in both type 1 and type 2 diabetic patients Pittenger et al., 2004; Shun et al., 2004; Drel et al., 2007). In streptozotocininduced diabetic animal models, reduced intraepidermal nerve fiber density was seen (Yan et al., 2012). However, it has been shown that hypoalgesia could be developed before small sensory nerve fiber degeneration (Beiswenger et al., 2008; Dobretsov et al., 2003). Studies showed that after steptozotocin injection, onset of hypersensitivities of mechanical stimuli could emerge as early as 1 week and mechanical hyperalgesia could be fully developed by 2-8 weeks (Chen, Pan 2002; Courteix et al., 1993; Malcangio et al., 1998). However, at least 6-10 months steptozotocin-induced diabetes are required for nerve morphological and funcational abnormalities, including changes in nerve microvessel and conduction velocity, to become apparent, suggesting the development of hyperalgesia may parallel or follow the development of hyperglycemia, metabolic and/or circulatory abnormalities in the steptozotocin diabetic models (Benstead, Sangalang 1995; Kalichman et al., 1998; Qiang et al., 1998).

Steptozotocin-induced diabetic animal models have also been used to study mechanical hyperalgesia and hypoalgesia. Elevated mechanical withdrawal thresholds in these models were associated with AR, oxidative stress, and PARP (Calcutt et al., 2004; Cameron et al., 2005; Dobretsov et al., 2007; Xu et al., 2012). It has been shown that in a mechanical hyperalgesia model, galanin receptor 1 expression was decreased in spinal dorsal horn and galanin receptor 2 expression was decreased in both dorsal root ganglion and spinal dorsal horn. Furthermore, 
galanin receptor 1 has been involved in the effect of attenuation of diabetic neuropathic pain (Xu et al., 2012). Methylglyoxalinduces post-translational modification of the nociceptor-specific sodium channel Nav 1.8 is involved in mechanical hyperalgesia (Francis et al., 2009).

Allodynia is the pain due to a stimulus that does not normally provoke pain. This condition occurs in approximately $30-50 \%$ of patients with DM (Vinik et al., 1995; Bastyr et al., 2005). However, it has not been studied in animal models as extensively as hyperalgesia or hypoalgesia. In one streptozotocin-induced diabetic mouse model, nocifensive behaviors are evoked by light touch of von Frey filaments to the paw (15g) (Chaplan et al., 1994). Nitrosative stress, PARP activation, increased excitability of dorsal root ganglion neurons and expression of Nav1.7 and p-EPK1/2 were thought to be associated with allodynia (Cameron et al., 2005; Ilnytska et al., 2006; Drel et al., 2007; Obrosova 2007). In another mechanical allodynia model, activation of both CB1 and CB2 has been shown to be involved in cannabinoidinduced relief of neuropathic pain (Vera et al., 2012).

Steptozotocin-induced diabetic rat models have been studied for understanding spontaneous inflammatory nociceptive behaviors which display exaggerated flinching behavior in both the first and second phases of the formalin test (Ilnytska et al., 2006). Several pathogenetic mechanisms have been identified, including increased activities of AR, PARP, and cyclooxygenase-299, as well as decreased neurotrophic support; and changes in signaling of GABA and potassium-chloride cotransporters (Cameron et al., 2005; Inytska et al., 2006; Ramos et al., 2007; Jolivalt et al., 2008 Jolivalt et al., 2008).

Some insights have been gained by testing antinociceptive agents in streptozotocin-induced diabetic animal models. For example, it has been shown that enhanced Rab7 lysosomal targeting of $\mu$-opioid receptors leads to loss of opioid antinociception in diabetic neuropathic pain. In addition, activation of muscarinic cholinergic receptors in the forebrain, and an increased expression of type- 2 metabotropic glutamate receptors in dorsal root ganglia neurons were identified in analgesia process of acetyl-L-carnitine. The process is thought to be mediated by acetylation of transcription factors of the nuclear factor (NK)-кB family (Mousa et al., 2013; Chiechio et al., 2007).

Overall, steptozotocin-induced diabetic animal models have been widely studied to understand diabetic neuropathic pain. The mechanism underlying hyperalgesia and abnormal sensation were identified as increased AR activity, oxidative-nitrosative stress, protein kinase C, PARP and ACE activations, C-peptide deficiency, impaired neurotrophism, and proinflammatory response (Meller et al., 1992; Cotter et al., 2002; Cameron et al., 2005; lnytska et al., 2006).

\section{Diet/Nutrition Induced Diabetic Animal Models}

In these models, rats or mice develop diabetes associated with obesity as a result of over nutrition, which mimic the metabolic syndrome in humans, and most require long period of dietary treatment. Sand rat, Tuco-Tuco and Spiny mouse are some models of diet/nutrition induced obesity and type 2 diabetes (Shafrir 2003).

In C57BL/6 J mice, type 2 diabetes was induced by simply feeding the mice with high fat diet. This mouse model is characterized with increased obesity, insulin resistance, hyperinsulinemia and increased serum total cholesterol levels (Surwit et al., 1988). In addition, baseline and fasting hyperglycemia were shown. These mice have been shown to develop peripheral leptin resistance.

Sand rat: Psammomys obesus ( $P$. obesus; Sand rat) develop obesity and type 2 diabetes when fed on high energy diet (Shafrir et al., 1999). The sand rats develop hyperphagia, obesity, glucose intolerance and hyperinsulinaemia. Eventually, these rats can develop $\beta$ cell degeneration and necrosis, insulin deficiency, overt diabetes and ketosis that could lead to death.

Decreased 2 deoxyglucose uptake and GLUT-4 protein and restrain hepatic gluconeogenesis were demonstrated with elevated phosphoenolpyruvate caboxykinase (PEPCK) activity. Increased proinsulin to insulin ratio in pancreatic $\beta$ cells was shown. Insulin support was required for survival of Sand rats at a late stage.

In C57BL/6J (ob/ob) mouse, onset of symptoms is genetically determined. When treated orally with, LAF237, an inhibitor of dipeptidyl peptidase-IV, these mice showed normalized glucose tolerance in association with augmented insulin secretion (Winzell, Ahren 2004).

In addition, Acomys calirinus (spiny mouse) showed weight gain and pancreatic $\beta$ cell hyperplasia, hypertrophy and increased pancreatic insulin content when on high energy diet. An impairment hormone release mechanism was demonstrated in these mice (Velasquez et al., 1990). These mice develop frank hyperglycemia with glucosuria leading to fatal ketosis.

Ctenomis talarum (Tucotuco) exhibits similar manifestations as sand rat and spiny mice when fed high energy diet. (Vogel, Vogel 1997) Peripheral neuropathy and, predominantly, small sensory fiber neuropathy, have been reported (Sumner et al., 2003; Pittenger et al., 2005; Papanas et al., 2011).

Diet/nutrition induced diabetic animal models have been studied for diabetic neuropathic pain. It was shown that a high-fat diet-fed mouse manifested alimentary obesity, hyperinsulinemia, and impaired glucose tolerance, leading to nerve conduction velocity deficit and small sensory fiber neuropathy, as well as increased sorbitol pathway activity, oxidative-nitrosative stress, and pro-inflammatory changes in PNS. More specifically, increased lipoxygenase activity has been implicated in endothelial dysfunction, an important factor in motor and sensory nerve conduction velocities deficits that associated with both diabetic and prediabetic neuropathy. In addition, lipoxygenase has been shown to be involved in high-fat-diet-induced inflammation (Cameron et al., 2001; Natarajan and Nadlerm 2003; Natarajan and Nadler 2004; Low et al., 1997; Cameron et al., 1997; Nakamura et al., 1999; Yagihashi et al., 2001; Obrosova et al., 2002). A major limitation to this approach is that most diet/nutrition induced diabetes animal models required long period time for induction. Therefore, these models are considered as long-term high-fat diet models.

\section{Models Induced by Combination of Diet/Nutrition and Streptozotocin $\nabla$}

Various studies showed the benefits of using the combination of nutrition- and streptozotocin-induced animal model. By using a combination of a high-fat diet and a streptozotocin inducer, diabetes can be induced more quickly. Different levels of high-fat diet and streptozotocin combinations have been studied. Some contain higher fat diet-fed and streptozotocin (30\% of high fat diet and $15 \mathrm{mg} / \mathrm{kg}$ of streptozotocin) (Zhang et al., 2003). Even 
though it takes a longer time to develop diabetes, these animals develop hyperglycemia, hyperinsulinemia, impaired glucose tolerance, insulin resistance and dyslipidemia. When lower fat diet-fed and higher-dose streptozotocin were used $(7 \%$ and $65 \mathrm{mg} / \mathrm{kg}$, respectively), it takes relatively shorter time to develop hyperglycemia, hyperinsulinemia, moderate insulin resistance, dyslipidemia and increased liver glycogen levels (Islam and Choi, 2007). However, total cholesterol and low density lipoproteincholesterol (LDL-C) levels are not as high as those with higher high-fat diet. When using higher high-fat-diet-fed plus higherdose of streptozotocin animal models $(40 \%$ and $50 \mathrm{mg} / \mathrm{kg}$ ), increased body weight, fasting blood glucose, triglyceride and free fatty acid levels were developed (Reed et al., 2000).Moderate high-fat diet-fed and moderate dose of streptozotocin animal models were used in some studies ( $20 \%$ and $40 \mathrm{mg} / \mathrm{kg}$ ) (Luo et al., 1998).

\section{Zucker diabetic fatty rat model}

The Zucker diabetic fatty (ZDF) is an outbred rat model that spontaneously progresses to frank diabetes due to failure to compensate adequately for insulin resistance. The homozygous mutation $(f a / f a)$ of the leptin hormone receptor is involved in the development of type 2 diabetes in male rats when they are fed a high-energy rodent diet (Hemmes and Schoch, 1988). Obese ZDF rats could have high levels of triglyceride and cholesterol. By using high saturated fat and sucrose-containing diets, very high lipid levels can be induced. In ZDF rats, the pancreatic islets were shown to have increased intraislet expression of ACE and angiotensin type 1 as well as increased intraislet fibrosis, apoptosis, and oxidative stress (Siwy et al., 2012). In addition, examination of ZDF rat somatic (sciatic) nerve has shown evidence of neuropathy similar to streptozotocin-rats as characterized by reduced conduction velocity and morphological changes in myelinated axons (Schmidt et al., 2003). It was reported that increased ACE and hydroxymethylglutaryl- CoA reductase activities, and neutral endopeptidase might be involved in sensory loss in Zucker fatty rats (Oltman et al., 2009; Oltman et al., 2008).

\section{BBZDP/Wor rat}

In addition to encoding the Leprfa mutation in ZDF rats, the BBZDP/Wor strain carries the Iddm2 type 1 diabetes associated genetic locus (Mordes et al., 2004). BBZDP/Wor rats develop lymphopenia, obesity, hyperinsulinemia, and autoimmune diabetes (Guberski et al., 1988). It is believed that BBZDP/Wor rat develop diabetes due to a combination of insulin resistance and autoimmune insulitis. Therefore, both type 1 and type 2 diabetes characteristics exist in this model.

\section{BBZDR/Wor rat}

BBZDR/Wor type 2 diabetic rat was developed by crossing BBZDP/Wor animals with the lean, nondiabetic BBDR/Wor rats, in order to remove the recessive Iddm2 gene responsible for lymphopenia and spontaneous autoimmunity and retain the Leprfa (fa1) mutation. Therefore, the BBZDR/Wor rat is an inbred rat model for type 2 diabetes. BBZDR/Wor diabetic rat has been shown to have dyslipidemia, hyperglycemia, insulin resistance, hypertension, and decreased levels of the $\beta$ cell-specific glucose transporter type-2 (GLUT-21) (Ellis et al., 1998). Furthermore, reduction of GLUT-2 staining of $\beta$-cell surface membranes has been observed.

The type 2 diabetic BBZDR/Wor and type 1 diabetic BBDP/Wor rat models have been studied for diabetic neuropathy. These 2 models show similarities and differences of disease pathogenesis. Progressive reduction of nerve conduction velocity, axonal atrophy, and degeneration, inactivation of $\mathrm{Na}+$-channels, intraaxonal $\mathrm{Na}+$ accumulation at the node, decreased $\mathrm{Na}+/ \mathrm{K}+$-ATPase, and nerve degeneration have been evident in both models. However, the slowing of nerve conduction velocities has been shown to be more severe in BBZDP/Wor rats than in BBZDR/Wor rats. On the other hand, BBZDR/Wor rats display a more severe $\mathrm{Na}+/ \mathrm{K}+$-ATPase defect. In BBZDP/Wor type 1 diabetes, disruption of the paranodal ion-channel barrier by axoglial dysjunction and paranodal demyelination have been demonstrated. While in BBZDR/Wor rats with type 2 diabetes, these structural changes have not been observed. Also, studies have shown that the perturbed insulin signaling due to insulin and/or C-peptide deficiency in type $1 \mathrm{BBDP} /$ Wor rats may account for the differences seen between these 2 diabetic models (Sima and Sugimoto, 1999; Sima et al., 2000). While in BB/Wor type 2 diabetes model, whole-cell, high-threshold, voltage-dependent calcium currents were enhanced in acutely dissociated, capsaicin-sensitive dorsal root ganglion neurones (Hall et al., 1995).

In a mechanical allodynia type 2 diabetic ZDF model, activation of $\mathrm{CB} 1$ has been shown to be involved in cannabinoid-induced relief of neuropathic pain (Obrosova et al., 2007). Another interesting finding is the reduced intraepidermal nerve fiber density in ZDF models (Oltman et al., 2008).

\section{Transgenic|Knock-out Diabetic Models \\ $\nabla$}

It has been shown that the behavioral changes of neuropathic pain in transgenic/knock-out diabetic models are strongly influenced by the specific knock-down of certain receptors such as the P2X3 receptor. In one animal model, 7 days after spinal nerve ligation, interestingly, the $\mathrm{P} 2 \mathrm{X} 3$ receptor expression was decreased in small diameter neurons of the L5-L6 DRG. However, the increase was not found in large diameter neurons in L5-L6 DRG as well as in both small and large diameter neurons in L4 DRG. Inhibitor RNA (iRNA) techniques may be used in future studies to reduce the compensatory genetic alternatives in knock-out animals (Kage et al., 2002).

\section{Limitations \\ $\nabla$}

Currently, available treatments for diabetic neuropathic pain are far from effective. Diabetic animal models have been widely used to identify new targets for diabetic neuropathic pain treatment. Even though models for studying diabetic neuropathic pain has identified a number of pathogenetic mechanisms implicated in diabetic painful and insensate neuropathy, the current models still have some limitations for diabetic neuropathic pain studies. Firstly, the life span of animal models is limited without obvious neuropathy. It is especially challenging to study how demyelination, axonal degeneration, fiber loss, or axonal regeneration contribute to diabetic neuropathic pain develop and progress. In addition, quantification of spontaneous pain in animals is technically challenging. Combination of multiple modalities, including streptozotocin and diet-nutrition, may be able to produce a more sophisticated animal model for diabetic neuropathic pain. In addition, gene expression profiling was explored for changes in mRNA transcripts in the dorsal root 


\begin{tabular}{lllllll} 
& $\begin{array}{l}\text { Onset of dia- } \\
\text { betes }\end{array}$ & Hyperglycemia & Insulin resistance & BW & TC & TC \\
\hline STZ-induced & short & yes & no & $\downarrow$ & \pm & \pm \\
\hline high fat diet & long & yes & yes & $\uparrow$ & $\uparrow$ & $\uparrow$ \\
\hline high fat diet/STZ & long & yes & yes & $\uparrow \downarrow$ & $\uparrow$ \\
\hline transgenic/knockout & short & yes & yes & $\downarrow$ & &
\end{tabular}

Table 1 Characteristics of diabetic animal models. ganglia and dorsal horn across multiple models of peripheral neuropathic pain. Further, sophisticated tools that have been developed and used in clinical studies including quantitative measurement of symptoms and signs and quantitative sensory testing may be adapted into animal models (Tegeder et al., 2006; Bennett et al., 2007; Hansson et al., 2007).

In conclusion, various animal models have been used to understand the mechanism underlying pathogenesis of diabetic neuropathic pain ( $\bullet$ Table 1 ). Some commonly shared pathways have been identified in the development of diabetic neuropathic pain, including increased AR, PKC, and PARP activities, nonenzymatic glycation/glycoxidation, and oxidative stress. However, pathogenesis of painful diabetic neuropathy is still waiting for further investigations. Identifying particular neurobiological mechanisms contributing to neuropathic pain in individuals and development of more sophisticated tools for measuring and categorizing neuropathic pain may advance the progress of diabetic neuropathic pain animal models.

\section{Conflict of interest: None.}

\section{References}

1 Bastyr EJ $3^{\text {rd }}$, Price KL, Bril V; the MBBQ Study Group. Development and validity testing of the neuropathy total symptom score-6: questionnaire for the study of sensory symptoms of diabetic peripheral neuropathy. Clin Ther 2005; 27: 1278-1294

2 Beiswenger KK, Calcutt NA, Mizisin AP. Dissociation of thermal hypoalgesia and epidermal denervation in streptozotocin-diabetic mice. Neurosci Lett 2008; 442: 267-272

3 Bennett MI, Attal N, Backonja MM et al. Using screening tools to identify neuropathic pain. Pain 2007; 127: 199-203

4 Benstead TJ, Sangalang VE. Nerve microvessel changes in diabetes are prevented by aldose reductase inhibition. Can J Neurol Sci 1995; 22: 192-197

5 Bierhaus A, Nawroth PP. Critical evaluation of mouse models used to study pain and loss of pain perception in diabetic neuropathy. Exp Clin Endocrinol Diabetes 2012; 120: 188-190

6 Bierhaus A, Fleming T, Stoyanov S et al. Methylglyoxal modification of Nav1.8 facilitates nociceptive neuron firing and causes hyperalgesia in diabetic neuropathy. Nat Med 2012; 18: 926-933

7 Bonner-Weir S, Trent DF, Weir GC. Responses of neonatal rat islet to streptozotocin. Limited B cell regeneration and hyperglycemia. Diabetes 1981; 30: 64-69

8 Boulton AJ. The diabetic foot: from art to science. The $18^{\text {th }}$ Camillo Golgi lecture. Diabetologia 2004; 47: 1343-1353

9 Calcutt NA. Potential mechanisms of neuropathic pain in diabetes. Int Rev Neurobiol 2002; 50: 205-208

10 Calcutt NA, Freshwater JD, Mizisin AP. Prevention of sensory disorders in diabetic Sprague-Dawley rats by aldose reductase inhibition or treatment with ciliary neurotrophic factor. Diabetologia 2004; 47 : 718-724

11 Cameron NE, Cotter MA, Basso M. Comparison of the effects of inhibitors of aldose reductase and sorbitol dehydrogenase on neurovascular function, nerve conduction and tissue polyol pathway metabolites in streptozotocin-diabetic rats. Diabetologia 1997; 40: 271-281

12 Cameron NE, Tuck Z, McCabe L et al. Effect of the hydroxyl radical scavenger, dimethylthiourea, on peripheral nerve tissue perfusion, conduction velocity and nociception in experimental diabetes. Diabetologia 2001; 44: 1161-1169
13 Cameron NE, Jack AM, Cotter MA. Effect of alpha-lipoic acid on vascular responses and nociception in diabetic rats. Free Radic Biol Med 2001; 31: $125-135$

14 Cameron NE, Gibson TM, Nangle MR et al. Inhibitors of advanced glycation end product formation and neurovascular dysfunction in experimental diabetes. Ann N Y Acad Sci 2005; 1043: 784-792

15 Chaplan SR, Bach FW, Pogrel JW et al. Quantitative assessment of tactile allodynia in the rat paw. J Neurosci Methods 1994; 53: 55-63

16 Chen SR, Pan HL. Hypersensitivity of spinothalamic tract neurons associated with diabetic neuropathic pain in rats. J Neuro-physiol 2002; 87: 2726-2733

17 Chiechio S, Copani A, Gereau RW $4^{\text {th }}$ et al. Acetyl-L-carnitine in neuropathic pain: experimental data. CNS Drugs 2007; 21 (Suppl 1): 31-38

18 Courteix C, Eschalier A, Lavarenne J. Streptozocin-induced diabetic rats: behavioural evidence for a model of chronic pain. Pain 1993; 53: $81-88$

19 Cotter MA, Jack AM, Cameron NE. Effects of the protein kinase $\mathrm{Cb}$ inhibitor LY333531 on neural and vascular function in rats with streptozotocin-induced diabetes. Clin Sci (Lond) 2002; 103: 311-321

20 Dobretsov M, Hastings SL, Romanovsky D et al. Mechanical hyperalgesia in rat models of systemic and local hyperglycemia. Brain Res 2003; 960: 174-183

21 Dobretsov M, Ghaleb AH, Romanovsky D et al. Impaired insulin signaling as a potential trigger of pain in diabetes and prediabetes. Int Anesthesiol Clin 2007; 45: 95-105

22 Devor M, Seltzer S. Pathophysiology of Damaged Nerves in Relation to Chronic Pain. London, England: Churchill Livingstone, 1999

23 Diabetes in America. $2^{\text {nd }}$ ed. NIH Publication 95-1468. Washington, DC: National Institutes of Health, National Institute of Diabetes and Digestive and Kidney Diseases, 1995

24 Drel VR, Pacher P, Vareniuk I et al. A peroxynitrite decomposition catalyst counteracts sensory neuropathy in streptozotocindiabetic mice. Eur J Pharmacol 2007; 569: 48-58

25 Drel VR, Pacher P, Vareniuk I et al. Evaluation of the peroxynitrite decomposition catalyst $\mathrm{Fe}(\mathrm{III})$ tetra-mesitylporphyrin octasulfonate on peripheral neuropathy in a mouse model of type 1 diabetes. Int J Mol Med 2007; 20: 783-792

26 Eaton SE, Harris ND, Ibrahim S et al. Increased sural nerve epineurial blood flow in human subjects with painful diabetic neuropathy. Diabetologia 2003; 46: 934-939

27 Ellis EA, Grant MB, Murray FT et al. Increased NADH oxidase activity in the retina of the BBZ/Wor diabetic rat. Free Radic Biol Med 1998; 24: $111-120$

28 Francis $G$, Martinez J, Liu W et al. Intranasal insulin ameliorates experimental diabetic neuropathy. Diabetes 2009; 58: 934-945

29 Guberski D, Butler L, Like A. The BBZ/Wor rat: An obese animal with autoimmune diabetes. In: Shafrir E, Renold A (eds.). Lessons from Animal Diabetes II. London: John Libbe and Company Ltd, 1988; 268-271

30 Hall KE, Sima AA, Wiley JW. Voltage-dependent calcium currents are enhanced in dorsal root ganglion neurones from the Bio Bred/ Worchester diabetic rat. J Physiol 1995; 486 (Pt 2): 313-222

31 Hansson P, Backonja M, Bouhassira D. Usefulness and limitations of quantitative sensory testing: Clinical and research application in neuropathic pain states. Pain 2007; 129: 256-259

32 Hemmes $R B$, Schoch $R$. High dosage testosterone propionate induces copulatory behavior in the obese male Zucker rat. Physiol Behav 1988; 43: 321-324

33 Ilnytska O, Lyzogubov VV, Stevens MJ et al. Poly(ADP-ribose) polymerase inhibition alleviates experimental diabetic sensory neuropathy. Diabetes 2006; 55: 1686-1694

34 Islam MS, Choi h. Nongenetic model of type 2 diabetes: a comparative study. Pharmacology 2007; 79: 243-249

35 Jafarnejad A, Bathaie SZ, Nakhjavani M et al. Effect of spermine on lipid profile and HDL functionality in the streptozotocin-induced diabetic rat model. Life Sci 2008; 82: 301-307 
36 Jolivalt CG, Vu Y, Mizisin LM et al. Impaired prosaposin secretion during nerve regeneration in diabetic rats and protection of nerve regeneration by a prosaposin-derived peptide. J Neuropathol Exp Neurol 2008; 67: 702-710

37 Jolivalt CG, Lee CA, Ramos KM et al. Allodynia and hyperalgesia in diabetic rats are mediated by GABA and depletion of spinal potassiumchloride co-transporters. Pain 2008; 140: 48-57

38 Kage K, Niforatos W, Zhu CZ et al. Alteration of dorsal root ganglion $\mathrm{P} 2 \mathrm{X} 3$ receptor expression and function following spinal nerve ligation in the rat. Exp Brain Res 2002; 147: 511-519

39 Kalichman MW, Dines KC, Bobik $M$ et al. Nerve conduction velocity, laser Doppler flow, and axonal caliber in galactose and streptozotocin diabetes. Brain Res 1998; 810: 130-137

40 Lenzen $S$. The mechanisms of allxan- and strptozotcin-induced diabetes. Diabetologia 2008; 51: 216-226

$41 \mathrm{Li} \mathrm{F}$, Drel VR, Szabó C et al. Low-dose poly(ADP-ribose) polymerase inhibitor-containing combination therapies reverse early peripheral diabetic neuropathy. Diabetes 2005; 54: 1514-1522

42 Low PA, Nickander KK, Tritschler HJ. The roles of oxidative stress and antioxidant. Treatment in experimental diabetic neuropathy. Diabetes 1997; 46 (suppl): S38-S42

43 Luo J, Quan J, Tsai J et al. Nongenetic mouse models of non-insulindependent diabetes mellitus. Metabolism 1998; 47: 663-668

44 Malcangio $M$, Tomlinson DR. A pharmacologic analysis of mechanical hyperalgesia in streptozotocin/diabetic rats. Pain 1998; 76: 151-157

45 Meller ST, Pechman PS, Gebhart GF et al. Nitric oxide mediates the thermal hyperalgesia produced in a model of neuropathic pain in the rat. Neuroscience 1992; 50: 7-10

46 Merskey H, Bogduk N. Classification of Chronic Pain: Descriptions of Chronic Pain Syndromes and Definitions of Pain Terms. $2^{\text {nd }}$ ed. Seattle, Wa: IASP Press, 1994

47 Mondelli M, Aretini A, Baldasseroni A. Distal symmetric polyneuropathy in diabetes. Differences between patients with and without neuropathic pain. Exp Clin Endocrinol Diabetes 2012; 120: 45-50

48 Mordes JP, Bortell R, Blankenhorn EP et al. Rat models of type 1 diabetes: Genetics, environment, and autoimmunity. ILAR J 2004; 45: 277-290

49 Morrow TJ. Animal models of painful diabetic neuropathy: the STZ rat model. Curr Protoc Neurosci 2004; Chapter 9: Unit 9.18

50 Mousa SA, Shaqura M, Khalefa BI et al. Rab7 silencing prevents $\mu$-opioid receptor lysosomal targeting and rescues opioid responsiveness to strengthen diabetic neuropathic pain therapy. Diabetes 2013; 62: $1308-1319$

51 Nakamura J, Kato K, Hamada $Y$ et al. A protein kinase C- $\beta$-selective inhibitor ameliorates neural dysfunction in streptozotocin-induced diabetic rats. Diabetes 1999; 48: 2090-2095

52 Natarajan $R$, Nadlerm JL. Lipoxygenases and lipid signaling in vascular cells in diabetes. Frontiers in Bioscience 2003; 8 (suppl): s783-s795

53 Natarajan $R$, Nadler JL. Lipid inflammatory mediators in diabetic vascular disease. Arteriosclerosis, Thrombosis, and Vascular Biology 2004; 24: 1542-1548

54 Obrosova IG, Drel VR, Oltman CL et al. Role of nitrosative stress in early neuropathy and vascular dysfunction in streptozotocin-diabetic rats. Am J Physiol Endocrinol Metab 2007; 293: E1645-E1655

55 Obrosova IG, Van Huysen C, Fathallah $L$ et al. An aldose reductase inhibitor reverses early diabetes-induced changes in peripheral nerve function, metabolism, and antioxidative defense. The FASEB Journal 2002; 16: 123-125

56 Obrosova IG, Xu W, Lyzogubov VV et al. PARP inhibition or gene deficiency counteracts intraepidermal nerve fiber loss and neuropathic pain in advanced diabetic neuropathy. Free Radic Biol Med 2008; 44: 972-981

57 Obrosova IG. Diabetic painful and insensate neuropathy: pathogenesis and potential treatments. Neurotherapeutics 2009; 6: 638-647

58 Oltman CL, Davidson EP, Coppey LJ et al. Attenuation of vascular/neural dysfunction in Zucker rats treated with enalapril or rosuvastatin. Obesity (Silver Spring) 2008; 16: 82-89

59 Oltman CL, Davidson EP, Coppey LJ et al. Treatment of Zucker diabetic fatty rats with AVE7688 improves vascular and neural dysfunction. Diabetes Obes Metab 2009; 11: 223-233

60 Papanas $N$, Vinik AI, Ziegler D. Neuropathy in prediabetes: does the clock start ticking early? Nat Rev Endocrinol 2011; 7: 682-690

61 Pittenger GL, Ray M, Burcus NI et al. Intraepidermal nerve fibers are indicators of small fiber neuropathy in both diabetic and non-diabetic patients. Diabetes Care 2004; 27: 1974-1979, 69

62 Pittenger GL, Mehrabyan A, Simmons $K$ et al. Small fiber neuropathy is associated with the metabolic syndrome. Metabolic Syndrome and Related Disorders 2005; 3: 113-121
63 Portha B, Giroix MH, Serradas P et al. Cellular basis for glucose refractoriness of pancreatic B-cells in non insulin dependent diabetes. In: Flatt PR, Lenzen $S$ (eds.). Insulin secretion and pancreatic B cell research. UK: Smith-Gordon, 1994; 461-472

64 Qiang $X$, Satoh J, Sagara $M$ et al. Inhibitory effect of troglitazone on diabetic neuropathy in streptozotocin-induced dia: betic rats. Diabetologia 1998; 41: 1321-1326

65 Quattrini C, Harris ND, Malik RA et al. Impaired skin microvascular reactivity in painful diabetic neuropathy. Diabetes Care 2007; 30: 655-659

66 Ramos KM, Jiang Y, Svensson CI et al. Pathogenesis of spinally mediated hyperalgesia in diabetes. Diabetes 2007; 56: 1569-1576

67 Reed MJ, Meszaros K, Entes $L J$ et al. A new rat model of type 2 diabetes: the fat-fed, streptozotocin-treated rat. Metabolism 2000; 49: 1390-1394

68 Richard S, Jonathan S, Paul Z et al. IDF Diabetes Atlas. fourth edition http://www.idf.org/diabetesatlas Accessed July 282013

69 Schmidt RE, Dorsey DA, Beaudet IN et al. Analysis of the Zucker Diabetic Fatty (ZDF) Type 2 Diabetic Rat Model Suggests a Neurotrophic Role for Insulin/IGF-I in Diabetic Autonomic Neuropathy. Am J Pathol 2003; 163: 21-28

70 Schreiber $A K$, Neufeld $M$, Jesus $C H$ et al. Peripheral antinociceptive effect of anandamide and drugs that affect the endocannabinoid system on the formalin test in normal and streptozotocin-diabetic rats. Neuropharmacology 2012; 63: 1286-1297

71 Shafrir E, Ziv E, Mosthaf L. Nutritionally induced insulin resistance and receptor defect leading to b cell failure in animal models. Ann NY Acad Sci 1999; 892: 223-246

72 Shafrir E. Diabetes in animals: Contribution to the understanding of diabetes by study of its etiopathology in animal models. In: Porte D, Sherwin RS, Baron A (eds.). Diabetes mellitus. NewYork: McGrawHill, 2003; 231-255

73 Shun CT, Chang YC, Wu HP et al. Skin denervation in type 2 diabetes: correlations with diabetic duration and functional impairments. Brain 2004; 127: 1593-1605

74 Sima AA, Sugimoto K. Experimental diabetic neuropathy: An update. Diabetologia 1999; 42: 773-788

75 Sima $A A$, Zhang $W, X u$ G et al. A comparison of diabetic polyneuropathy in type II diabetic BBZDR/Wor rats and in type I diabetic BB/Wor rats. Diabetologia 2000; 43: 786-793

76 Siwy J, Zoja C, Klein J et al. Evaluation of the Zucker Diabetic Fatty (ZDF) Rat as a Model for Human Disease Based on Urinary Peptidomic Profiles. PLoS One 2012; 7: e51334

77 Srinivasan $K$, Ramarao P. Animal models in type 2 diabetes research: an overview. Indian J Med Res 2007; 125: 451-472

78 Sumner CJ, Sheth S, Griffin JW et al. The spectrum of neuropathy in diabetes and impaired glucose tolerance. Neurology 2003; 60: 108-111

79 Surwit RS, Kuhn CM, Cochrane C et al. Diet-induced type II diabetes in C57BL/6J mice. Diabetes 1988; 37: 1163-1167

80 Szkudelski $T$. The mechanism of alloxan and streptozotocin action in B cells of the rat pancreas. Physio Res 2001; 50: 536-546

81 Szkudelski T. Streptozotocin-nicotinamide-induced diabetes in the rat. Characteristics of the experimental model. Experimental biology and medicine 2012; 237: 481-490

82 Tegeder I, Costigan M, Griffin RS et al. GTP cyclohydrolase and tetrahydrobiopterin regulate pain sensitivity and persistence. Nat Med 2006; 12: 1269-1277

83 Vareniuk I, Pavlov IA, Obrosova IG. Inducible nitric oxide synthase gene deficiency counteracts multiple manifestations of peripheral neuropathy in a streptozotocin-induced mouse model of diabetes. Diabetologi 2008; 51: 2126-2133

84 Velasquez MT, Kimmel PL, Michaelis OE IV. Animal models of spontaneous diabetic kidney disease. FASEB J 1990; 4: 2850-2859

85 Vera G, López-Miranda V, Herradón E et al. Characterization of cannabinoid-induced relief of neuropathic pain in rat models of type 1 and type 2 diabetes. Pharmacol Biochem Behav 2012; 102: 335-343

86 Veves A, Backonja M, Malik RA. Painful diabetic neuropathy: epidemiology, natural history, early diagnosis, and treatment options. Pain Med 2008; 9: 660-674

87 Vinik AI, Suwanwalaikorn S, Stansberry KB et al. Quantitative measurement of cutaneous perception in diabetic neuropathy. Muscle Nerve 1995; 18: 574-584

88 Vogel HG, Vogel WH. Drug discovery and evaluation; Pharmacological assays. Heidelberg, Berlin: Springer-Verlag, 1997

89 Winzell MS, Ahren B. The high-fat diet-fed mouse: a model for studying mechanisms and treatment of impaired glucose tolerance and type 2 diabetes. Diabetes 2004; 53 (Suppl 3): S215-S219 
90 WHO. Country and regional data on diabetes http://www.who.int/ diabetes/facts/world_figures/en/ Accessed November 19, 2013

$91 \mathrm{Xu} X$, Liu Z, Liu $\mathrm{H}$ et al. The effects of galanin on neuropathic pain in streptozotocin-induced diabetic rats. Eur J Pharmacol 2012; 680: 28-33

92 Yagihashi S, Yamagishi SI, Wada RI et al. Neuropathy in diabetic mice overexpressing human aldose reductase and effects of aldose reductase inhibitor. Brain 2001; 124: 2448-2458
93 Yan JE, Yuan W, Lou X et al. Streptozotocin-induced diabetic hyperalgesia in rats is associated with upregulation of Toll-like receptor 4 expression. Neurosci Lett 2012; 526: 54-58

94 Zhang $\mathrm{F}$, Ye C, Li G et al. The rat model of type 2 diabetic mellitus and its glycometabolism characters. Exp Anim 2003; 52: 401-407

95 Zhang JL, Yang JP, Zhang JR et al. Gabapentin reduces allodynia and hyperalgesia in painful diabetic neuropathic rats by decreasing expression level of Nav1.7 and p-ERK1/2 in DRG neurons. Brain Res 2013 Epub 2012 Nov 23 